Article

\title{
Empirical Analysis of Parking Behaviour of Conventional and Electric Vehicles for Parking Modelling: A Case Study of Beijing, China
}

\author{
Chengxiang Zhuge ${ }^{1,2,3}$, Chunfu Shao ${ }^{4}$ and $\mathrm{Xia} \mathrm{Li}^{5, *}$ \\ 1 Department of Geography, University of Cambridge, Downing Place, Cambridge CB2 3EN, UK \\ 2 Tyndall Centre for Climate Change Research, University of East Anglia, Norwich NR4 7TJ, UK \\ 3 Department of Land Surveying and Geo-Informatics, The Hong Kong Polytechnic University, Hung Hom, \\ Kowloon, Hong Kong 999077, China \\ 4 Key Laboratory of Transport Industry of Big Data Application Technologies for Comprehensive Transport, \\ Beijing Jiaotong University, 3 Shangyuancun, Xizhimenwai, Beijing 100044, China \\ 5 School of Management and Economics, Beijing Institute of Technology, Beijing 100081, China \\ * Correspondence: xiali@bit.edu.cn; Tel.: +86-010-68918057
}

Received: 1 July 2019; Accepted: 7 August 2019; Published: 9 August 2019

check for updates

\begin{abstract}
An empirical study of the parking behaviour of Conventional Vehicles (CVs), Battery Electric Vehicles (BEVs), and Plug-in Hybrid Electric Vehicles (PHEVs) was carried out with the data collected in a paper-based questionnaire survey in Beijing, China. The study investigated the factors that might influence the parking behaviour, with a focus on the maximum acceptable time of walking from parking lot to trip destination, parking fee, the availability of charging posts, the state of charge of EVs and the range anxiety of BEVs. Several Multinomial Logit (MNL) models were developed to explore the relationships between individual attributes and parking choices. The results suggest that (1) the maximum acceptable walking time generally increases with the rise in the amount of saving for parking fee; (2) the availability of charging posts does not influence the maximum acceptable walking time when PHEVs and BEVs have sufficient charge, but the percentage of people willing to walk longer than eight minutes increases from around 35\% to $46 \%$ when PHEVs are in a low stage of charge; (3) more than half of BEV drivers want the driving range of their vehicles to be one and a half times the driving distance before they depart, given the distance is $50 \mathrm{~km}$. Based on the empirical findings above, a conceptual framework was proposed to explicitly simulate the parking behaviour of both CVs and EVs using agent-based modelling.
\end{abstract}

Keywords: parking behaviour; charging behaviour; electric vehicles; Multinomial Logit (MNL) model; Beijing; agent-based modelling

\section{Introduction}

Explicit modelling of travel behaviour has received increasing attention over the past few decades, for example, using activity-based models [1,2], agent-based models [3,4] and dynamic traffic assignment [5]. As one key part of travel behaviour, parking behaviour received substantial attention in such explicit modelling [6,7].

\subsection{General Parking Behaviour of Conventional Vehicles (CVs)}

In order to better understand parking behaviour and further provide empirical findings for the explicit modelling of parking behaviour, many empirical studies have been conducted. These studies can be categorized according to different criteria [8]: 
- Types of Data Used: In general, data on parking behaviour can be collected using either or both stated preference [9] and/or revealed preference [10] techniques.

- Trip Purposes: Previous studies have tried to investigate one particular trip purpose, such as work [11], and two or more purposes [12].

- Models Used: Discrete choice models have been one of the most-used approaches to exploring parking-related choice behaviours, including Binary Logit Model [13], Multinomial Logit Model [14], Mixed Logit Model [15] and Nested Logit Model [11].

- Number of Study Areas: Previous studies have been focused on one study area [16] and also carried out comparative studies of multiple study areas [15].

A recent special issue on "Economics of Parking" in the Journal of Transport Economics and Policy offers some new insights into parking behaviour of CV [17], such as the relationship between parking fee and retail $[18,19]$, residential parking $[20,21]$ and cruising for parking $[10,16,22]$. However, these studies paid little attention to the difference between CVs and Electric Vehicles (EVs) in parking behaviour.

\subsection{Parking Behaviour of Electric Vehicles (EVs)}

Recently, EVs, including Battery Electric Vehicles (BEVs) and Plug-in Hybrid Electric Vehicle (PHEVs), has received considerable attention from academia, government and industry, as EVs are a core module of a smart and sustainable transport system: on one hand, using EVs instead of CVs can reduce the direct vehicular emissions from vehicles, and thus can improve the local air quality. But the net reduction in emissions also depends on how the electricity is generated in terms of energy sources used (e.g., coal and wind) [23-25]; on the other hand, Vehicle-to-Grid [26], which allows the commutations between EV drivers and smart grid, can promote the development of a smart city.

Some attempts have been made to explicitly model the EV enroute travel behaviour mainly using activity-based models, such as MATSim [27] and Feathers [28]. However, these studies have tended to pay less attention to parking behaviour of EV. One reason may be that there were few empirical findings that can used for the explicit modelling. The parking behaviour of EVs mainly differs from that of $\mathrm{CVs}$ in additionally considering the destination-based charging behaviour, as EVs can be recharged at parking lots with charging posts available. Therefore, the availability of charging posts could increase the attractiveness of the parking lots and may heavily influence the parking behaviour of EVs.

Many empirical studies have been carried out to provide insights into the charging behaviour of EVs, using various methods, including the mixed logit model [29,30], data mining model [31] and expected utility theory [32]. Some of them investigated the behaviour of choosing the time when EV users charge their vehicles [29,33]. For instance, Sun, Yamamoto and Morikawa [29] analysed the behaviour of choosing the time when BEV users charge their vehicles. Some studies investigated the behaviour of choosing the locations where they charge [33-35]. Speidel and Bräunl [34] found that most EV drivers charged at business and home locations in the Western Australian, using the real data collected from both EVs and charging stations during the period from 2010 to 2012. Morrissey, Weldon and O'Mahony [35] found that, in most cases, EV users charged at home, and chose parking lots for public charging. Some of the empirical studies tried to explore how the EV travel behaviour may vary across user types. Robinson, Blythe, Bell, Hübner and Hill [33] compared the recharging behaviours of private users, organisation individuals and organisation pool vehicles, suggesting that these users differed from each other in both the time when they recharged their EVs and the places where they recharged. Sun, Yamamoto and Morikawa [30] investigated how private and commercial users might differ in the maximum acceptable distance of diverting to fast charging stations on their journeys. Apart from the differences across EV user types, in the time when to charge and the locations where to charge, the desired state of charge [36] and the response of EV drivers to the dynamic pricing of charging services [32] have also been studied. 


\subsection{Research Gaps}

As reviewed above, many empirical studies have been carried out to investigate the general parking behaviour of $\mathrm{CV}$, which mainly differed from each other in the types of data used, trip purposes, models used and the number of study areas. These empirical findings have been further used to explicitly model parking behaviour, for example, using activity-based modelling and agent-based modelling. With the increasing adoption of EVs, the travel behaviour of EV, which is additionally involved in charging behaviour, has received rising attention. Several empirical studies have been carried out to investigate how charging behaviour of EVs may differ across the EV user types, in the time when they charge, and in the location where they charge.

At the early stage of transportation electrification, most of the charging events take place at trip destinations (e.g., workplaces and home) through charging posts at parking lots. However, the correlation between parking and charging behaviours have received little attention. In response, this paper attempts to investigate the charging behaviour of EVs at trip destinations (or parking lots), with a focus on the difference between BEVs and PHEVs in the maximum acceptable time of walking from parking lots to destination, given different states of charge and the availability of charging posts.

Furthermore, the range anxiety has been commonly viewed as one of the main barriers to the uptake of EVs [37-39]. However, the possible correlation between the range anxiety and parking behaviour has not been well understood. In response, this paper will also investigate the relationship between the distance between trip origin and destination and the desirable driving range which the BEV driver wants to obtain before his departure.

In addition to the above factors associated with the parking behaviour of EVs, the parking fee, which was commonly viewed as a critical factor to parking and travel demand [40-46], will also be investigated in this paper, with a focus on how a parking fee may influence the maximum acceptable time of walking from a parking lot to trip destination.

In summary, this paper will investigate both general and EV-related factors that can potentially influence parking behaviours of both CVs and EVs, considering the possible correlation between parking and charging behaviours of EV and the possible relationship between parking fee and the maximum acceptable time of walking from a parking lot to trip destination. In order to take heterogeneity into account, several discrete choice models will be developed to explore the correlation and relationship. The empirical findings are expected to be useful for explicitly modelling parking behaviours of both CVs and EVa at the individual level, considering socio-demographic characteristics (e.g., income), infrastructural factors (e.g., the availability of charging posts), psychological factors (e.g., range anxiety) and vehicular factors (e.g., states of charge of EV).

\section{Methodology}

\subsection{Questionnaire Design}

In order to fill in the research gas identified above, a questionnaire survey was designed to collect the essential data on parking behaviours of CVs and EVs, with a particular focus on the maximum acceptable time of walking from a parking lot and trip destination, given different parking fees, vehicle types, and states of charge, as well as the availability of charging posts at parking lots. Since BEVs, PHEVs and charging posts might be new to respondents, they were introduced in detail in the questionnaire (see Appendix A for their introductions).

Specifically, the questionnaire was composed of two parts: Part 1 is about socio-demographic characteristics (e.g., sex, income and vehicle ownership); Part 2 is about the parking behaviours of $\mathrm{CVs}$, PHEVs, and BEVs. They are mainly used to collect the information on (1) the trade-off between walking time and parking fees; (2) the maximum acceptable walking time for both PHEVs and BEVs (given different states of charge and the availability of charging posts); (3) battery-related concerns (e.g., BEV driving range); and (4) individual- and household-level attributes. The information will be used to answer the following three research questions: 


\section{Q1: How do people make a trade-off between parking fee and walking time?}

Parking fees have been commonly viewed as an important factor directly and indirectly influencing the parking behaviour of drivers $[40,43,46]$. In order to investigate whether and how parking fee may influence general parking behaviour, the respondents were asked to choose the maximum acceptable time of walking from a parking lot to trip destination if they could save 5, 10 and 20 RMB in total within the following scenarios:

Given two parking lots A and B: Parking lot A is very close to your destination and you almost do not need to walk; while parking lot B is a bit far away and you need to walk for a while. Please choose your maximum acceptable walking time if you can save a specific parking fee as shown in Table 1.

Table 1. Three Scenarios for Testing the Sensitivity of Parking Fee.

\begin{tabular}{|c|c|c|c|c|}
\hline Scenarios & & Your Choic & num Acce & Walking Time?) \\
\hline \multirow{3}{*}{ If you choose parking lot $B$, you will save ... } & $5 \mathrm{RMB}$ & $\begin{array}{l}\text { A. } 3 \mathrm{~min} \\
\text { D.10 min }\end{array}$ & $\begin{array}{l}\text { B. } 5 \text { min } \\
\text { E.15 min }\end{array}$ & $\begin{array}{l}\text { C. } 8 \mathrm{~min} \\
\text { F. Others: }\end{array}$ \\
\hline & $10 \mathrm{RMB}$ & $\begin{array}{l}\text { A. } 3 \mathrm{~min} \\
\text { D. } 10 \mathrm{~min}\end{array}$ & $\begin{array}{l}\text { B. } 5 \mathrm{~min} \\
\text { E.15 min }\end{array}$ & $\begin{array}{l}\text { C.8 min } \\
\text { F. Others: }\end{array}$ \\
\hline & $20 \mathrm{RMB}$ & $\begin{array}{l}\text { A. } 3 \mathrm{~min} \\
\text { D.10 min }\end{array}$ & $\begin{array}{l}\text { B. } 5 \text { min } \\
\text { E.15 min }\end{array}$ & $\begin{array}{l}\text { C. } 8 \mathrm{~min} \\
\text { F. Others: }\end{array}$ \\
\hline
\end{tabular}

\section{Q2: How may the availability of charging posts influence the parking behaviour of EVs?}

Both PHEVs and BEVs can be recharged when they are connected to the power grid, for example, through charging posts that are mostly installed at workplaces and home. Therefore, those parking lots with charging posts available may be more attractive to EV drivers. The respondents were asked about the maximum acceptable time of waking from parking lot to trip destination given different vehicle types and states of charge in the following three scenarios:

Imagine that you will first go to Destination 1 (see Figure 1) which has two parking lots available: Parking Lot A without charging posts and Parking Lot B with charging posts available, and then you will go to Destination 2 that has Parking Lot $C$ with charging posts available. It should be noted that $A$ is just next to Destination 1 and you almost do not to need to walk, but $B$ is a little far away. What is the maximum acceptable time of walking from Parking Lot $B$ to Destination 1 if you can get your vehicles charged when (1) you are driving a PHEV with sufficient charge; (2) you are driving a PHEV with insufficient charge, but sufficient petrol; and (3) you are driving a BEV with sufficient charge.

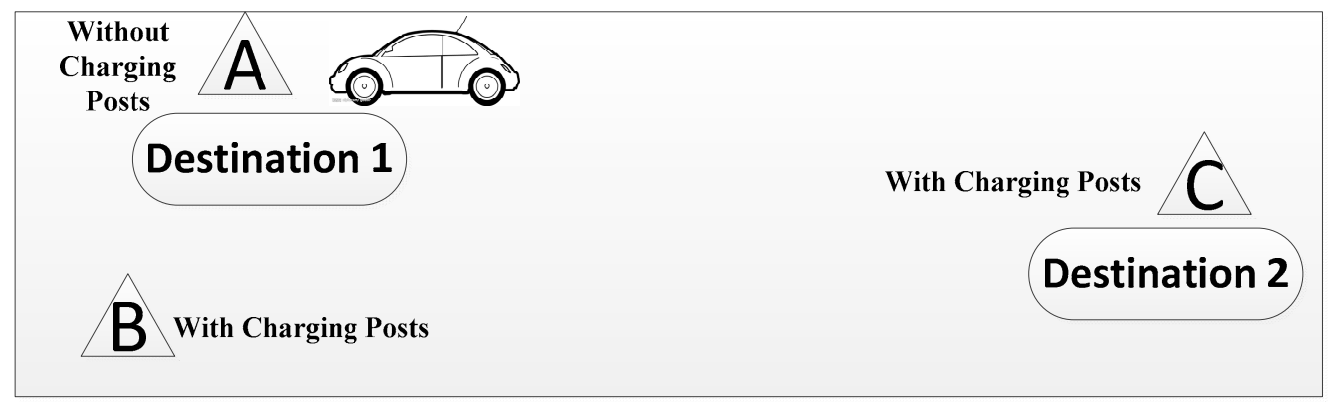

Figure 1. The scenario for testing the availability of charging posts at parking lots.

\section{Q3: How may the range anxiety influence the charging behaviour at parking lot?}

Currently, the limited driving range has been viewed as one of the main barriers to the widespread adoption of EVs, and the range anxiety is a basic characteristic of EV drivers. In order to somewhat explore how the range anxiety may influence the charging behaviour at parking lots, the respondents were further asked what the minimum driving range they thought was enough to drive from Destination 1 to Destination 2 (see Figure 1), given that Destination 1 is about $50 \mathrm{~km}$ far away from Destination 2 
where charging posts are available. The information can be further used to estimate the duration of charging (or parking) at parking lots.

\subsection{Survey Design}

We used the capital of China, Beijing as a case study. The Beijing government had very positive attitudes towards EVs, as evident from its efforts in the development of infrastructure development and several EV-related policies, such as the license plate lottery policy and the end-number license plate policy. The survey was conducted at shopping malls across all of the 16 administrative regions in Beijing, targeting driving license holders who are in principle able to drive vehicles [25]. It was hoped that the respondents could imagine how they might park EVs, given different EV types and states of charge, as well as the availability of charging posts. The survey was additionally used to collect the data on refuelling and charging behaviours of CVs and EVs, as detailed in [25], where a more detailed description of the survey can be found.

\subsection{Statistical Analysis of Heterogenous Parking Behaviour: Multinomial Logit (MNL) Model}

The discrete choice model is a typical approach to exploring heterogenous individual behaviours (e.g., travel behaviour) and is thus adopted here to analyse parking behaviour [47]. Specifically, we will use the Multinomial Logit (MNL) model, which is one typical type of discrete choice model and has also been widely in the analysis of parking behaviour $[9,48,49]$, as reviewed above. With the MNL model, we will try to explore the potential linkage between socio-demographic attributes and maximum acceptable time of walking from a trip destination to parking lot, given different parking fees, vehicle types and states of charge of EVs.

We identified a set of individual- and household- level attributes (including sex, income, age, education level, number of driving licenses and number of vehicles owned) for the MNL models to be developed, based on the previous studies of parking and charging behaviours, which suggested that socio-demographic attributes were associated with both parking [50,51] and charging [52,53] behaviours. Some specific empirical findings are as follows: [48] examined the possible influences of sex, income and age on drivers' choice of car parks, and found that people with higher incomes tended not to choose those parks which take a long walking time to research; Bonsall and Palmer observed different parking behaviours associated with education level and gender [54]. Zhuge, Shao and Li suggested that both the numbers of driving licenses and vehicles owned were associated with charging behaviour of EVs [25]. Nurul Habib, et al. indicated that people with more vehicles owned were more likely to choose fee-charging parking type [55].

Since MNL is a typical model and has been widely used, we will only give a brief introduction. More technical details can be found in [24,25]. In a typical MNL model, we can have two or more choices or alternatives. For example, alternatives in this paper can be different maximum acceptable walking times (e.g., $3 \mathrm{~min}$ and $5 \mathrm{~min}$ ). The total number of alternatives is denoted as $J$. The probably $\left(P_{n i}\right)$ for an individual $n$ to choose a specific choice or alternative $i$ can be calculated by Equation (1) $[24,25]$.

$$
P_{n i}=\frac{e^{u_{n i}}}{\sum_{j=1}^{J} e^{u_{n i}}}
$$

where $u_{n i}$ is the utility of alternative $i$ for individual $n$. We can further decompose $u_{n i}$ into an observable component $V_{n i}$ and unobservable component (that can be assumed to follow a specific distribution) [24,25]. The observable component, $V_{n i}$, can be calculated by Equation (2).

$$
V_{n i}=X_{n} \cdot \beta_{i}
$$

where $X_{n}=\left(X_{n, 1}, X_{n, 2}, \ldots, X_{n, M}\right)$ is the vector of observable variables. Here, these observable variables are socio-demographic characteristics, such as age, gender and the number of driving licenses owned. $\beta_{i}=\left(\beta_{i, 1}, \beta_{i, 2}, \ldots, \beta_{i, M}\right)$ is a set of coefficients for alternative $i$. Here, we used Stata [56], which is a 
typical statistical software package, to estimate these parameters with the survey data collected in Beijing [24,25].

\section{Survey Results}

\subsection{General Results}

The survey had 601 samples in total. The distributions of the characteristics of participants and their households, including age, income, education level, and the number of vehicles owned, are analysed in Appendix B. Furthermore, we also investigate the correlation between individual income and education level, and find that the correlation is not very strong.

\subsection{The Influence of Parking Fee}

Three different scenarios (see Section 2.1) were set up to investigate how parking fees may influence the maximum acceptable time of waking from parking lot to trip destination, given that the respondents could save 5, 10 and 20 RMB in parking fees, respectively. Figure 2 shows the distributions of the walking time for these three scenarios, suggesting that with the increase in the amount of saving, the maximum acceptable walking time is on the rise. For example, only around $30 \%$ of the respondents were willing to walk longer than $5 \mathrm{~min}$ when they can save $5 \mathrm{RMB}$ for parking fee; it increases to around $46 \%$ when they can save $10 \mathrm{RMB}$ and to around $61 \%$ when they can save $20 \mathrm{RMB}$; Furthermore, the percentage of respondents who are willing to walk longer than 8 min changes slightly (from around $11 \%$ to $12 \%$ ) when the saving is increased from 5 to $10 \mathrm{RMB}$, but it increases very significantly when the saving is increased to $20 \mathrm{RMB}$, accounting for $46 \%$. This indicates that the relationship between the maximum acceptable walking time and parking fee is nonlinear.

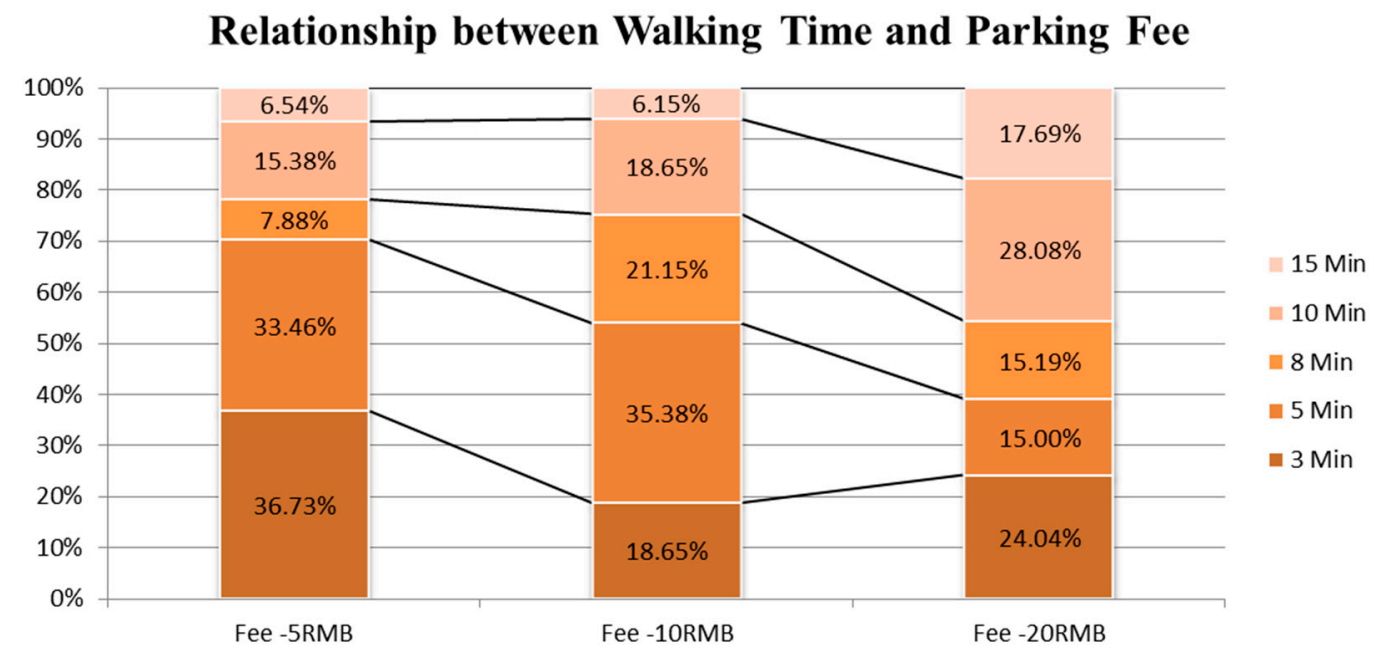

Figure 2. Relationship between the walking time and parking fee.

In order to further explore if the influence of parking fee on the maximum acceptable walking time relates to any socio-demographic characteristics, three Multinomial Logit (MNL) models were developed for the saving of 5, 10 and $20 \mathrm{RMB}$, respectively (see Table 2). According to the $\mathrm{z}$ values, the statistically significant variables for each scenario are identified as follows:

Case 1: Parking Fee -5 RMB. Sex is identified as the only statistically significant variable. Furthermore, females can bear longer walking time than males given that they can save 5 RMB for parking fee, according to the model coefficients and Figure A2 (in Appendix C) presenting the relationship between the influence on walking time and sex.

Case 2: Parking Fee -10 RMB. Compared to saving 5 RMB, saving 10 RMB is additionally statistically significant to the level of education, apart from sex. Specifically, people with a higher level 
of education could accept a longer walking time and the choice of an 8-min walk is more preferable to them, which can also be found in Figure A3 (in Appendix C), which shows the relationship between the influence of saving $10 \mathrm{RMB}$ on walking time and the two significant variables.

Case 3: Parking Fee -20 RMB. Apart from sex, which is a statistically significant variable in both Cases 1 and 2, the other significant variables include individual income and age. According to the coefficients and the relationships shown by Figure A4 (in Appendix C), the following conclusions can be made: (1) Sex: a significant variable for people accepting a 10-min walk as the maximum, which is more preferable to males; (2) Individual Income: a significant variable for Choice $1(=3 \mathrm{~min})$, and people with higher income are more likely to accept a short walking time, as, perhaps, the time values of these people are generally higher and thus they are less likely to be sensitive to a high parking fee; (3) Age: another significant factor only for Choice 1, and people with a higher age are less likely to choose a 3-min walk, presumably as older people tend to have more time available and may want to save parking fees by choosing parking lots further away.

Table 2. Multinomial logit (MNL) models for the influence of parking fee on walking time.

\begin{tabular}{|c|c|c|c|c|c|c|}
\hline \multirow[b]{2}{*}{ Walking Time } & \multicolumn{2}{|c|}{ Parking Fee -5 RMB } & \multicolumn{2}{|c|}{ Parking Fee -10 RMB } & \multicolumn{2}{|c|}{ Parking Fee -20 RMB } \\
\hline & Coef. & $\mathrm{z}$ value & Coef. & z value & Coef. & z value \\
\hline \multicolumn{7}{|c|}{ Choice 1 = 3 Min } \\
\hline Age & & & & & -0.317046 & -2.07 \\
\hline Education & & & 0.3005372 & 1.67 & & \\
\hline Indincome & & & & & 0.1819307 & 2.11 \\
\hline Sex & -0.92659 & -2.44 & -0.779752 & -1.86 & -0.228113 & -0.79 \\
\hline LicenseNum & & & -0.397464 & -0.53 & & \\
\hline VehicleNum & & & & & 0.5519227 & 1.84 \\
\hline Constant & 3.091553 & 5 & 1.412477 & 0.74 & -0.309081 & -0.32 \\
\hline \multicolumn{7}{|c|}{ Choice 2 = 5 Min } \\
\hline Age & & & & & -0.141183 & -0.84 \\
\hline Education & & & 0.4422604 & 2.6 & & \\
\hline Indincome & & & & & 0.1487178 & 1.55 \\
\hline Sex & -0.776529 & -2.04 & -0.691521 & -1.76 & -0.214762 & -0.66 \\
\hline LicenseNum & & & -0.964162 & -1.35 & & \\
\hline VehicleNum & & & & & 0.0691371 & 0.2 \\
\hline Constant & 2.791432 & 4.48 & 2.270291 & 1.25 & -0.129166 & -0.12 \\
\hline \multicolumn{7}{|c|}{ Choice 3 = 8 Min } \\
\hline Age & & & & & -0.06501 & -0.4 \\
\hline Education & & & 0.5880812 & 3.15 & & \\
\hline Indincome & & & & & 0.0517238 & 0.55 \\
\hline Sex & -0.802962 & -1.7 & -0.831337 & -2 & -0.309132 & -0.96 \\
\hline LicenseNum & & & -1.065447 & -1.39 & & \\
\hline VehicleNum & & & & & 0.1808234 & 0.53 \\
\hline Constant & 1.382781 & 1.85 & 1.300065 & 0.66 & -0.096586 & -0.09 \\
\hline \multicolumn{7}{|c|}{ Choice $4=10$ Min } \\
\hline Age & & & & & -0.196092 & -1.35 \\
\hline Education & & & 0.4213494 & 2.29 & & \\
\hline Indincome & & & & & 0.0800174 & 0.96 \\
\hline Sex & -0.921205 & -2.2 & -0.64047 & -1.53 & -0.596636 & -2.1 \\
\hline LicenseNum & & & -0.874026 & -1.14 & & \\
\hline VehicleNum & & & & & -0.32002 & -1.03 \\
\hline Constant & 2.213973 & 3.31 & 1.498277 & 0.77 & 2.349504 & 2.46 \\
\hline \multicolumn{7}{|c|}{ Note: Choice 5 (=15 Min) is the base outcome } \\
\hline
\end{tabular}

Overall, the extent to which the saving of parking fee can influence the maximum acceptable walking time is closely associated with several individual attributes, including sex, age, individual income and education level. Among them, sex tends to be more influential, as it is a statistically significant factor in all three cases with the saving of 5 RMB, 10 RMB and 20 RMB. Sex appears to influence how drivers trade off parking fee and walking time somehow. For example, given that 
drivers can save $5 \mathrm{RMB}$ for parking, a long waking time (or 10-min walking) tends to more acceptable to females. However, when the amount saved increases from $5 \mathrm{RMB}$ to $20 \mathrm{RMB}$, it becomes for acceptable to males.

\subsection{A Comparative Study of Parking Behaviours of BEV and PHEV}

Another three different scenarios (see Section 2.1) were set up to explore whether and how the availability of charging posts at parking lots may influence (or increase) the maximum acceptable walking time, given that the respondents were driving PHEVs with sufficient charge, PHEVs with insufficient change (but sufficient petrol) and BEVs with sufficient change. Figure 3 shows the distributions of the maximum acceptable walking time in these three scenarios, indicating that the availability of charging posts does not influence when EVs (either PHEVs or BEVs) have sufficient charge, as evident from the almost identical percentages for each choice. However, the percentage of people willing to walk longer than 8 min increases from around $35 \%$ to $46 \%$ when PHEVs are in a low stage of charge, due to the attractiveness of charging posts available at parking lots.

\section{Distribution of the Walking Time with Diffeerent States of Charge}

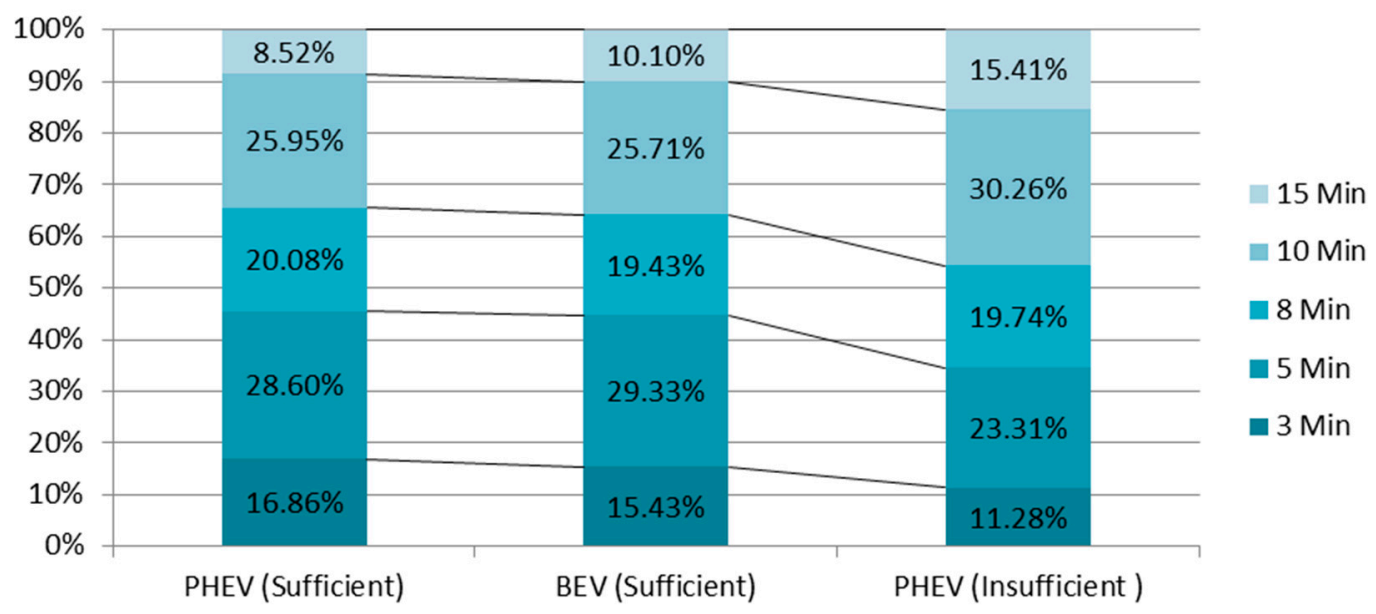

Figure 3. Distribution of the maximum acceptable walking time with different states of charge.

In order to further investigate whether the influence of the availability of charging posts is associated with any socio-demographic characteristics, another three Multinomial Logit (MNL) models (see Table 3) were developed for the three different scenarios, namely PHEVs with sufficient charge, PHEVs with insufficient charge (but sufficient petrol) and BEVs with sufficient charge. According to the $\mathrm{z}$ values, the statistically significant variables in each scenario are identified as follows:

Case 1: PHEVs with sufficient charge. Sex is identified as the only statistically significant factor influencing the maximum acceptable walking time. Specifically, females are less likely to choose a 10-min walk as their maximums, and males do not have a significant preference for the acceptable walking time, as also evident from Figure A5 (in Appendix D) representing the relationship between the walking time and sex.

Case 2: PHEVs with insufficient charge (but sufficient petrol). Age and education level are identified as statistically significant variables influencing the walking time. Specifically, people with a higher level of education tend to accept a longer walking time (Choice 5 with a 15-min walk and Choice 4 with a 10-min walk), as also evident from Figure A6 (in Appendix D) representing the relationships between the walking time and the two significant variables. This may be because well-educated people have stronger environmental awareness and therefore are more willing to use electricity. According to the coefficients of age and Figure A6 (in Appendix D), it can be roughly concluded that older people 
are more likely to accept a longer walking time, this may be because they in general have more time available and lower time values and therefore hope to save money through using electricity.

Case 3: BEVs with sufficient charge. The statistically significant variables are household income and the number of vehicles owned. Specifically, people with more vehicles tend to choose a relatively long walking time (10 min or above), as also evident from Figure A7 (in Appendix D); in addition, people with higher household income tend to prefer shorter walking time. This is likely because these people may have higher time values and do not want to spend much time on walking, though charging and using electricity can save money.

In summary, the choices of walking time are associated with completely different socio-demographic characteristics when the respondents were given different EV types and different states of charge, and the statistically significant variables are briefly listed as follows for each case:

- PHEVs with sufficient charge-Sex;

- PHEVs with insufficient charge-Age and education level;

- BEVs with sufficient charge-Household income and the number of vehicles owned.

Table 3. MNL models for the influence of the availability of charging posts on the walking time.

\begin{tabular}{|c|c|c|c|c|c|c|}
\hline \multirow{2}{*}{ Walking Time } & \multicolumn{2}{|c|}{ PHEV (Sufficient) } & \multicolumn{2}{|c|}{ PHEV (Insufficient ) } & \multicolumn{2}{|c|}{ BEV (Sufficient) } \\
\hline & Coef. & $z$ value & Coef. & $\mathrm{z}$ value & Coef. & z value \\
\hline \multicolumn{7}{|c|}{ Choice 1 = 3 Min } \\
\hline Age & & & -0.443081 & -2.37 & & \\
\hline Education & & & -0.374984 & -2.17 & & \\
\hline Sex & 0.0660901 & 0.18 & & & & \\
\hline HouIncome & & & & & 0.3592022 & 2.06 \\
\hline VehicleNum & & & & & -0.639558 & -1.63 \\
\hline Constant & 0.5844975 & 1.03 & 3.323677 & 2.64 & 0.9812186 & 1.1 \\
\hline \multicolumn{7}{|c|}{ Choice 2 = 5 Min } \\
\hline Age & & & -0.167095 & -1.11 & & \\
\hline Education & & & -0.235379 & -1.55 & & \\
\hline Sex & -0.255404 & -0.75 & & & & \\
\hline HouIncome & & & & & 0.358516 & 2.22 \\
\hline VehicleNum & & & & & -0.887167 & -2.49 \\
\hline Constant & 1.57716 & 3.01 & 2.353227 & 2.12 & 2.181667 & 2.7 \\
\hline \multicolumn{7}{|c|}{ Choice 3 = 8 Min } \\
\hline Age & & & -0.31517 & -1.98 & & \\
\hline Education & & & -0.21266 & -1.35 & & \\
\hline Sex & -0.132172 & -0.37 & & & & \\
\hline HouIncome & & & & & 0.331195 & 1.95 \\
\hline VehicleNum & & & & & -0.944234 & -2.46 \\
\hline Constant & 1.048463 & 1.91 & 2.55387 & 2.22 & 1.969183 & 2.28 \\
\hline \multicolumn{7}{|c|}{ Choice 4 = 10 Min } \\
\hline Age & & & -0.37386 & -2.54 & & \\
\hline Education & & & -0.096791 & -0.65 & & \\
\hline Sex & -0.717245 & -2.04 & & & & \\
\hline HouIncome & & & & & 0.342629 & 2.1 \\
\hline VehicleNum & & & & & -0.547569 & -1.54 \\
\hline Constant & 2.103539 & 3.97 & 2.50321 & 2.3 & 1.327651 & 1.63 \\
\hline \multicolumn{7}{|c|}{ Note: Choice 5 (=15 Min) is the base outcome } \\
\hline
\end{tabular}

\subsection{The Influence of Range Anxiety of BEV Drivers}

In order to investigate how the limited driving range of BEV relates to the anxiety of drivers, we set up a scenario about the minimum driving range people want to have before their departures, given a specific travel distance of $50 \mathrm{~km}$. Figure $4 \mathrm{a}$ shows the distribution of the minimum driving range and Figure $4 \mathrm{~b}$ shows the distribution of the ratio of the minimum driving range to the travel distance (that is $50 \mathrm{~km}$ in this case), suggesting that the number of people choosing higher range rises gradually and 
then goes down sharply after the turning point with the range of $80 \mathrm{~km}$, which accounts for about $32 \%$. In addition, more than half of BEV drivers (about $56 \%$ ) want the driving range of their vehicles to be one and a half times the driving distance (about $75 \mathrm{~km}$ in total) before their departures.

In order to further explore if range anxiety is associated with any socio-demographic characteristics, an MNL model was developed, as shown by Table 4. According to the $\mathrm{z}$ values, the statistically significant variables are the highest level of education, number of driving licenses, and number of vehicles owned. Specifically, people with more vehicles owned in their households, or with a higher level of education, tend to choose a higher driving range; oppositely, people with more driving licenses owned in their households have a tendency of choosing a lower driving range from $55 \mathrm{~km}$ to $70 \mathrm{~km}$ (or a ratio of driving range to travel distance ranging from 1.1 to 1.2). These conclusions are made based on both the model coefficients and Figure A8 (in Appendix E) that presents the relationships between the minimum driving range and significant variables.

Table 4. MNL model for the minimum driving ranges of BEVs.

\begin{tabular}{|c|c|c|c|c|c|c|}
\hline BEV Driving Range & Coef. & Std. Err. & z & $\mathbf{P}>\mathbf{z}$ & \multicolumn{2}{|c|}{ [95\% Conf.Interval] } \\
\hline \multicolumn{7}{|c|}{ Choice $1=55 \mathrm{~km}$} \\
\hline VehicleNum & -0.42947 & 0.442247 & -0.97 & 0.331 & -1.29626 & 0.437319 \\
\hline Education & -0.74948 & 0.203826 & -3.68 & 0 & -1.14897 & -0.34999 \\
\hline LicenseNum & 1.64212 & 0.822484 & 2 & 0.046 & 0.03008 & 3.254159 \\
\hline Constant & 1.67083 & 2.116229 & 0.79 & 0.43 & -2.4769 & 5.818563 \\
\hline \multicolumn{7}{|c|}{ Choice $2=60 \mathrm{~km}$} \\
\hline VehicleNum & -0.30374 & 0.350236 & -0.87 & 0.386 & -0.99019 & 0.382709 \\
\hline Education & -0.2634 & 0.189578 & -1.39 & 0.165 & -0.63496 & 0.108172 \\
\hline LicenseNum & 1.552505 & 0.681592 & 2.28 & 0.023 & 0.216609 & 2.8884 \\
\hline Constant & -0.32831 & 1.879291 & -0.17 & 0.861 & -4.01165 & 3.355031 \\
\hline \multicolumn{7}{|c|}{ Choice $3=70$ km } \\
\hline VehicleNum & -0.70268 & 0.340072 & -2.07 & 0.039 & -1.36921 & -0.03615 \\
\hline Education & -0.26739 & 0.181346 & -1.47 & 0.14 & -0.62282 & 0.088046 \\
\hline LicenseNum & 1.373702 & 0.652634 & 2.1 & 0.035 & 0.094564 & 2.652841 \\
\hline Constant & 1.26546 & 1.794359 & 0.71 & 0.481 & -2.25142 & 4.78234 \\
\hline \multicolumn{7}{|c|}{ Choice $4=80 \mathrm{~km}$} \\
\hline VehicleNum & -0.73018 & 0.324226 & -2.25 & 0.024 & -1.36565 & -0.09471 \\
\hline Education & -0.16696 & 0.177314 & -0.94 & 0.346 & -0.51449 & 0.180566 \\
\hline LicenseNum & 1.084067 & 0.617689 & 1.76 & 0.079 & -0.12658 & 2.294715 \\
\hline Constant & 1.596194 & 1.728342 & 0.92 & 0.356 & -1.7913 & 4.983682 \\
\hline \multicolumn{7}{|c|}{ Choice $5=90 \mathrm{~km}$} \\
\hline VehicleNum & 0.211941 & 0.413675 & 0.51 & 0.608 & -0.59885 & 1.02273 \\
\hline Education & -0.28725 & 0.224196 & -1.28 & 0.2 & -0.72666 & 0.152169 \\
\hline LicenseNum & 1.122391 & 0.814865 & 1.38 & 0.168 & -0.47471 & 2.719497 \\
\hline Constant & -1.35403 & 2.247921 & -0.6 & 0.547 & -5.75987 & 3.051817 \\
\hline \multicolumn{7}{|c|}{ Note: Choice $6(=100 \mathrm{~km})$ is the base outcome } \\
\hline
\end{tabular}




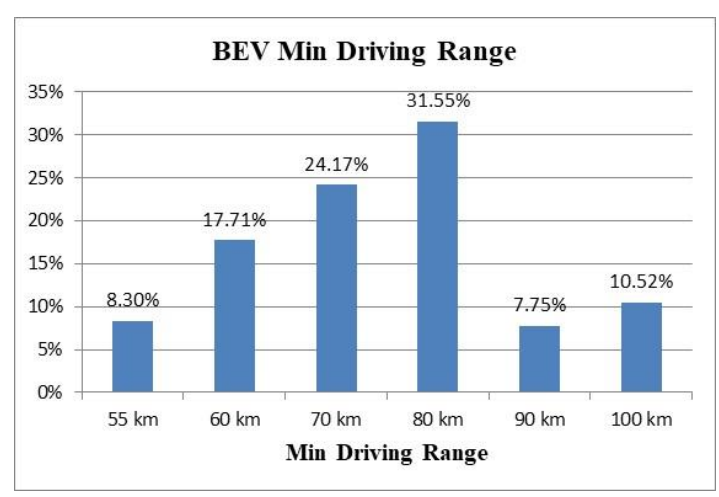

(a)

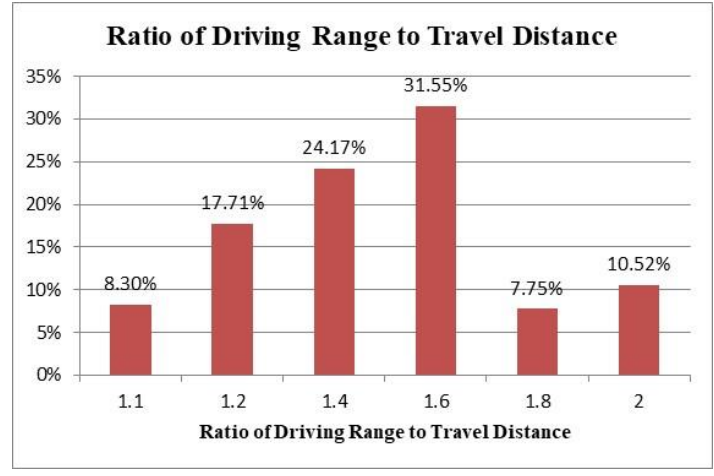

(b)

Figure 4. Distributions of min driving range and ratio of driving range to travel distance: (a) Min driving ranges; (b) Ratio of driving range to travel distance.

\section{A Conceptual Design for Agent-Based Modelling of Parking Behaviour with the Empirical Findings}

The empirical findings obtained above would be useful for explicit modelling of parking behaviour, considering heterogenous charging and parking behaviours, which are associated with socio-demographic characteristics, vehicle types, vehicle states and the availability of infrastructures. Such an explicit model would help to figure out spatiotemporal distributions of both parking and charging demands, which can be further used for infrastructure optimization and planning.

Agent-based modelling is a typical approach to modelling individual behaviour [57-60], such as travel behaviour, and thus is adopted here to show how the empirical findings can be used for explicit modelling of parking and charging behaviours, taking heterogeneity into account. Specifically, the modelling here will be focused on the decision-making of drivers on the maximum acceptable time of walking from trip destination to parking lot $\left(T_{\text {Walking }}\right)$, which has received relatively scant attention in the studies of EV charging and parking behaviours.

We set up a scenario (see Figure 5) to demonstrate how to develop a spatially and temporally explicit parking model using agent-based modelling and empirical findings $[6,61,62]$ :

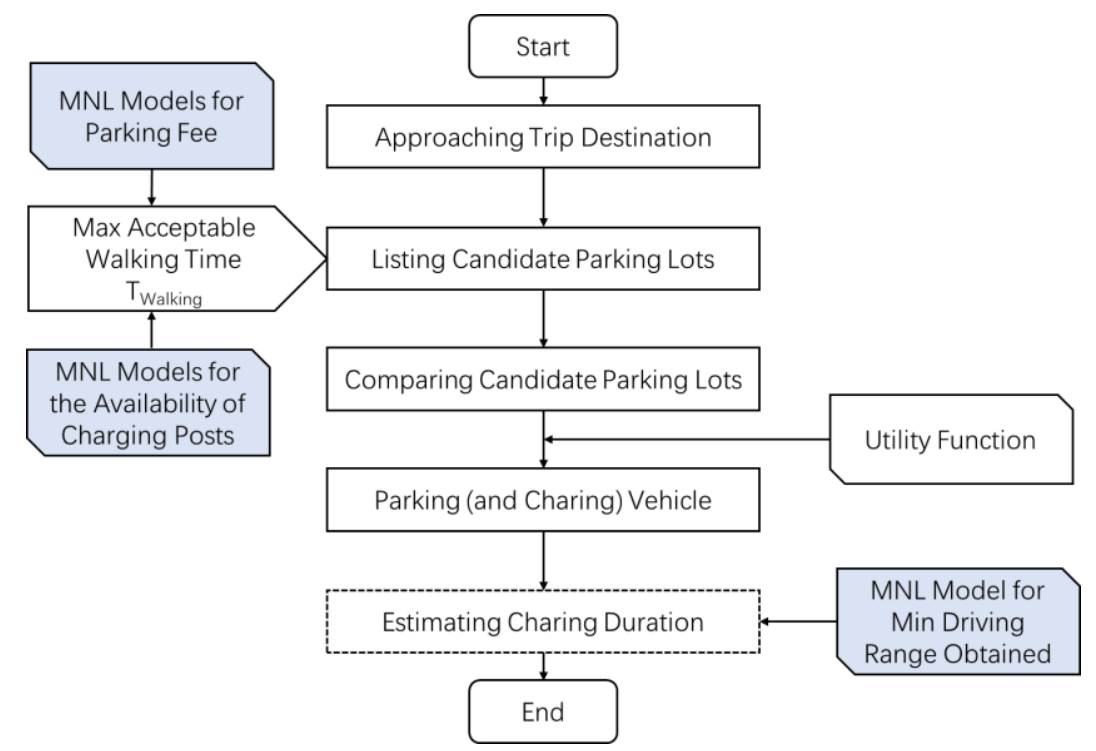

Figure 5. Illustration of parking and charging behaviour modelling.

Step 1. Generating Candidate Parking Lots. When a driver agent approaches its destination, it will firstly list those candidate parking lots that fall into its maximum acceptable walking time 
( $\left.T_{\text {Walking }}\right)$, which may vary from one to another. As the empirical findings suggested, parking fee is an important factor that could influence $T_{\text {Walking: }}$ with the decrease of parking fee, the maximum acceptable time of waking from a parking lot to trip destination is likely to increase. Therefore, the three Multinomial Logit (MNL) models for parking fee (see Table 2) can be used to estimate $T_{\text {Walking }}$ for each agent based on their socio-demographic characteristics (e.g., age and income). For EVs, another three MNL models (see Table 3) can be used to extra consider the influence of the availability of charging posts on $T_{\text {Walking. }}$

Step 2: Comparing Candidate Parking Lots. Then, the driver agent will further compare the candidate parking lots in its list and choose the one with the highest utility considering the utilities of parking fee $\left(U_{\text {ParkingFee }}\right)$, the time of walking from a parking lot to trip destination $\left(U_{\text {WalkingTime }}\right)$ and the availability of charging posts at parking lots $\left(U_{\text {ChargingPost }}\right)$, which are the three influential factors identified in this empirical study, as represented by Equation (3) $[7,61]$.

$$
U_{\text {Parking }}=U_{\text {ParkingFee }}+U_{\text {WalkingTime }}+U_{\text {ChargingPost }}+\varepsilon
$$

where, $\varepsilon$ denotes the random term representing those unobservable factors.

For those EV drivers, range anxiety can also be somewhat considered with the empirical findings obtained. Specifically, the MNL model for the minimum driving range obtained (see Table 4) can be used to roughly calculate the ratio of the minimum driving range to the distance between the current location and the next location where charging facilities are available. Then the ratio can be further used to estimate the minimum driving range for each $\mathrm{EV}$ driver when they recharge at parking lots, based on whether the charging duration (equal to parking duration) and electricity consumption can be estimated.

\section{Conclusions}

A paper-based questionnaire survey was carried out in Beijing, China to collect the data on parking behaviour of Conventional Vehicles (CVs), Battery Electric Vehicles (BEVs) and Plug-in Hybrid Electric Vehicles (PHEVs), covering all of the 16 administrative regions, with 601 samples obtained in total. The data was further used to investigate the key factors potentially influencing parking behaviours of both CVs and EVs, with a focus on the maximum acceptable time of walking from parking lot to trip destination, parking fee and range anxiety. In order to relate parking behaviour to socio-demographic characteristics (e.g., age), several Multinomial Logit (MNL) Models were developed. The key empirical findings are summarized as follows:

(1) With the increase in the amount saved for parking fee, the maximum acceptable walking time is on the rise, but the relationship between the walking time and parking fee is nonlinear. In addition, the estimated MNL models for parking fee indicate that the influence of parking fee is closely associated with several individual attributes, including sex, age, individual income and education level. Among them, sex tends to be more influential and appears to influence how drivers make a trade-off between parking fee and walking time;

(2) The availability of charging posts does not influence the maximum acceptable walking time when EVs (either PHEVs or BEVs) have sufficient charge. However, the percentage of people willing to walk longer than $8 \mathrm{~min}$ increases from around $35 \%$ to $46 \%$ when PHEVs are in a low stage of charge, due to the attractiveness of charging posts at parking lots;

(3) Given that the next destination with charging facilities available would be $50 \mathrm{~km}$ far away, more than half of BEV drivers (about 56\%) want the driving range of their vehicles to be one and a half times the driving distance (about $75 \mathrm{~km}$ in total) before their departures.

Based on the empirical findings above, a conceptual framework for agent-based modelling of parking behaviour was proposed to explicitly simulate how CV and EV drivers choose their parking lots, considering socio-demographic characteristics, the availability of charging posts, the influence of parking fee and states of charge of EVs. The agent-based parking model can be further integrated into 
an activity-based travel demand model, so as to estimate the usage of and demand for parking lots at the disaggregate level, which can be used for planning and optimizing the layouts of parking lots and charging posts.

The work has been limited in the following aspects: (1) the MNL models for parking behaviours of CVs and EVs only used one of the most-used variable types, namely socio-demographic attributes. Incorporating other variables (e.g., trip purpose) would potentially increase the model accuracy. However, this would increase the survey cost (time and money), and also the resulting models would become computationally expensive when they are coupled with agent-based models in large-scale scenarios. In this study, we made a trade-off between survey cost and model accuracy, but the study can be easily improved if one needs a better understanding of the parking behaviours or a more explicit model; (2) the conceptual parking model assumes that drivers would want to walk for a longer time from parking lot to trip destination, when they can save parking fee. This may vary from one to another and thus was simulated with the MNL models considering socio-demographic attributes. However, some other factors, such as the condition of the parking lot, would also influence the maximum acceptable walking time, which has not been taken into account in the model; in addition, the model can also be improved by considering the availability of parking spaces and possible cruising for parking, as cruising was found as influential to parking [10,16,22].

Author Contributions: C.Z. designed the survey and analyzed the results; C.S. advised on the survey design and analysis of results; X.L. advised on methodology and applying empirical findings. All the authors wrote and edited the paper.

Funding: This research was funded by the National Natural Science Foundation of China (grant numbers 51678044; 71401012), the Fundamental Research Funds for the Central Universities (NO. 2017JBZ106), China, the Hong Kong Polytechnic University [1-BE2J], and the Hebei Natural Science Foundation (grant number E2016513016).

Conflicts of Interest: The authors declare no conflict of interest.

\section{Appendix A. Questionnaire Design}

In the questionnaire, BEV, PHEV and Slow Charging Posts were introduced as follows:

- Plug-in Hybrid Electric Vehicle (PHEV): runs on both electricity and petrol. The vehicle can still run on petrol when the electricity is used up. The electric driving range is around $50 \mathrm{~km}$ and the petrolic range is the same as that of a conventional vehicle.

- Battery Electric Vehicle (BEV): only runs on electricity. Its driving range is about 150 to $200 \mathrm{~km}$.

- Charging Post: is one common charging facility and is mostly located at parking lots. Drivers can connect their electric vehicles to charging posts and get their vehicles charged when they are parked. It takes around $8 \mathrm{~h}$ to fully charge a battery electric vehicle, which means you can obtain around $25 \mathrm{~km}$ driving range with one-hour charging and can save 8 Yuan, compared with refuelling.

\section{Appendix B. General Results of the Survey}

Figure A1 shows the basic characteristics of participants and their households in the survey, including sex, age, individual monthly income, highest level of education, job type, household income per year, number of driving licenses in a household, number of children in a household, number of vehicles owned by a household and number of household members. In addition, we also investigated the relationship between individual income and education level (see Figure A1) and found that there seems to be no strong relationship between them. Specifically, with the increase in education level, the percentage of people with an income above $15 \mathrm{k}$ RMB is on the rise, but the income from 10 to $15 \mathrm{k}$ RMB decreases first and then increases and levels off. Furthermore, for those participants with high education level (namely Graduate Degree), many of them (over $40 \%$ ) have a relatively low income below $8 \mathrm{k}$ RMB. In addition, the correlation coefficient for these two variables is 0.23 , suggesting that they are positively correlated, but the correlation is not very strong. 


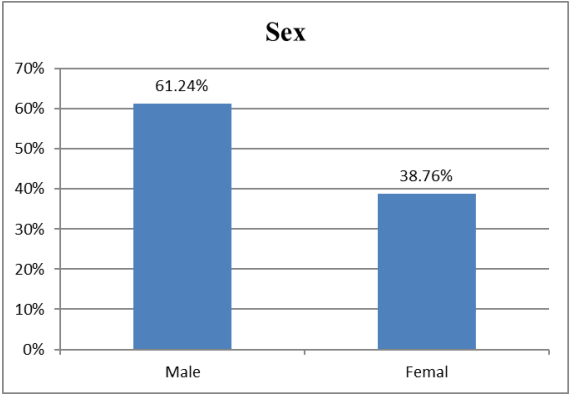

(a)

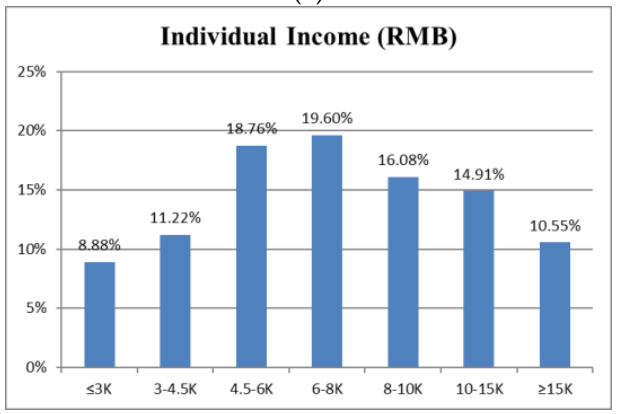

(c)

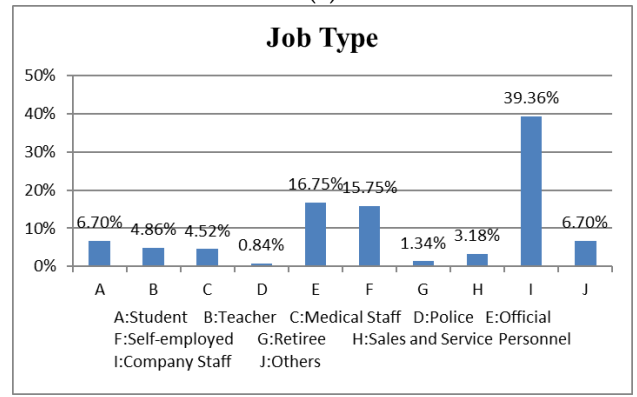

(e)

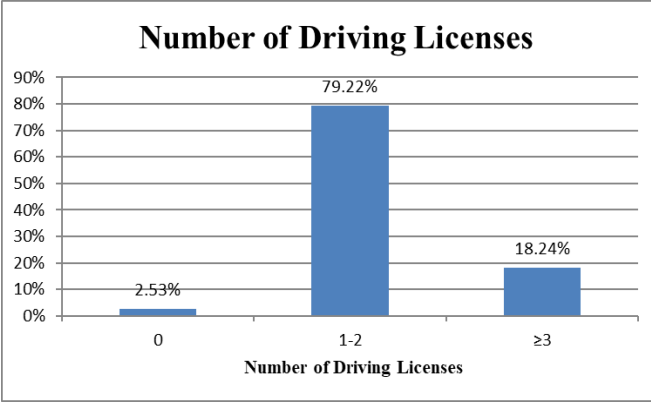

(g)

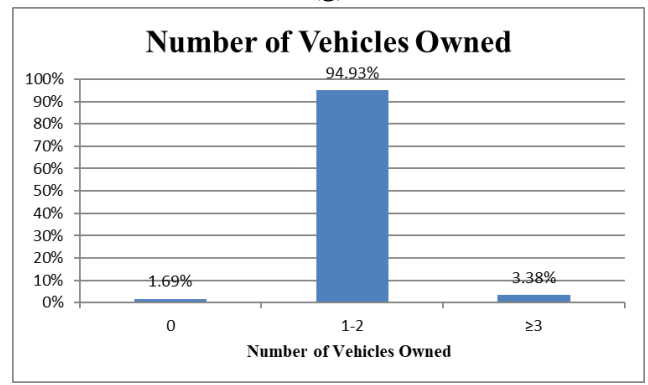

(i)

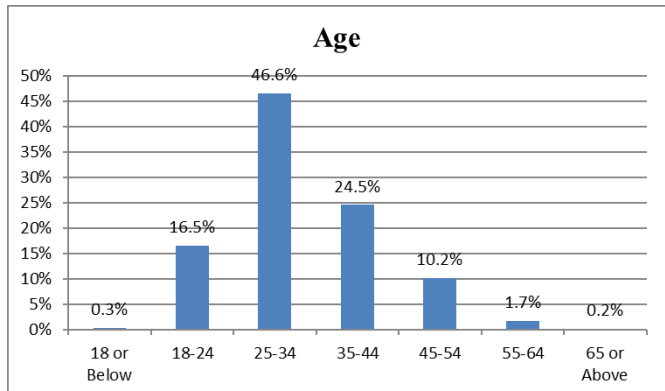

(b)

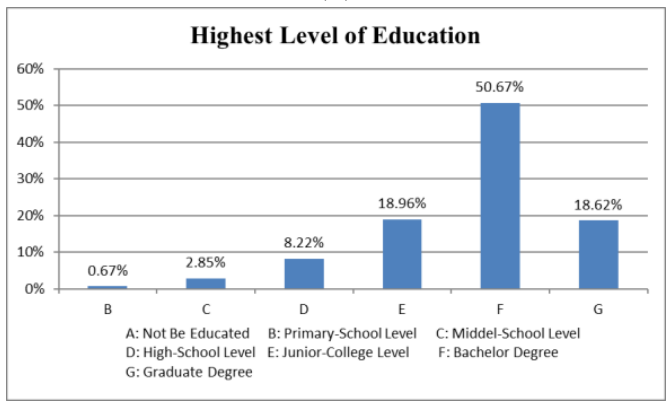

(d)

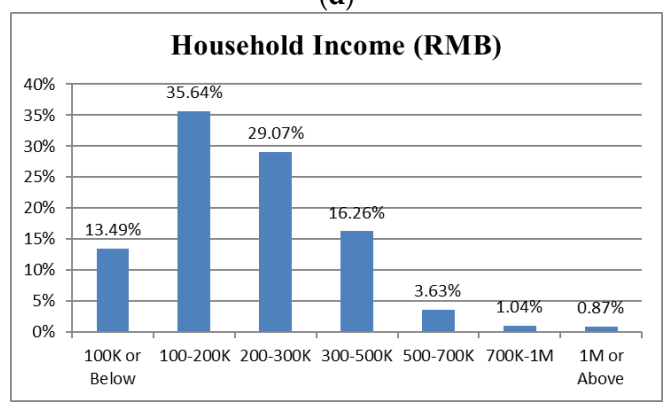

(f)

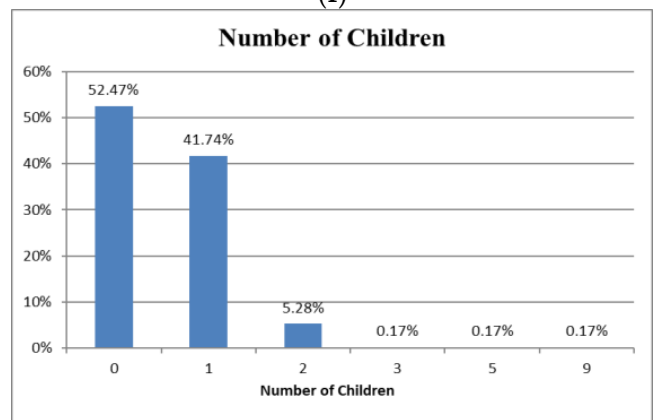

(h)

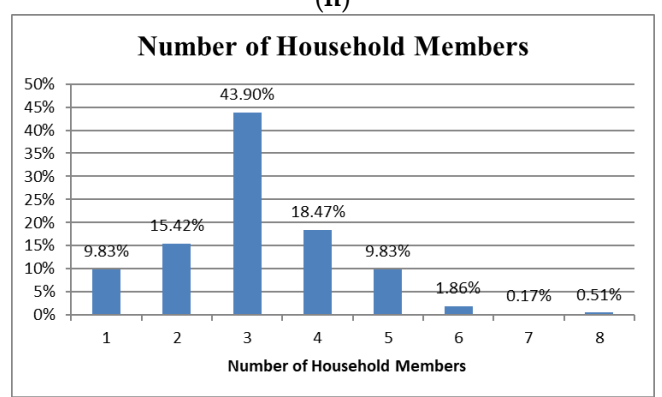

(j)

Figure A1. Cont. 


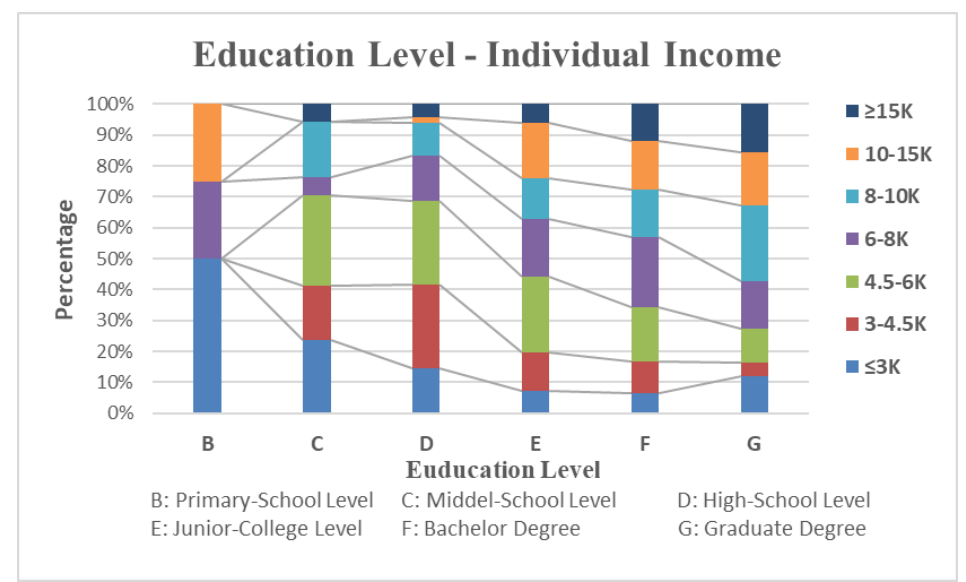

(k)

Figure A1. Characteristics of Participants and their Households. (a) Sex; (b) Age; (c) Individual Monthly Income (RMB); (d) Highest Level of Education; (e) Job Type; (f) Household Income per Year (RMB); (g) Number of Driving Licenses in a Household; (h) Number of Children in a Household; (i) Number of Vehicles Owned by a Household; (j) Number of Household Members; (k) Relationship between Education Level and Individual Income (Correlation Coefficient $=0.23$, note that we used the group index for the calculation).

\section{Appendix C. Figures for Parking Fee}

Appendix C.1. Case 1: Saving 5 RMB for Parking Fee

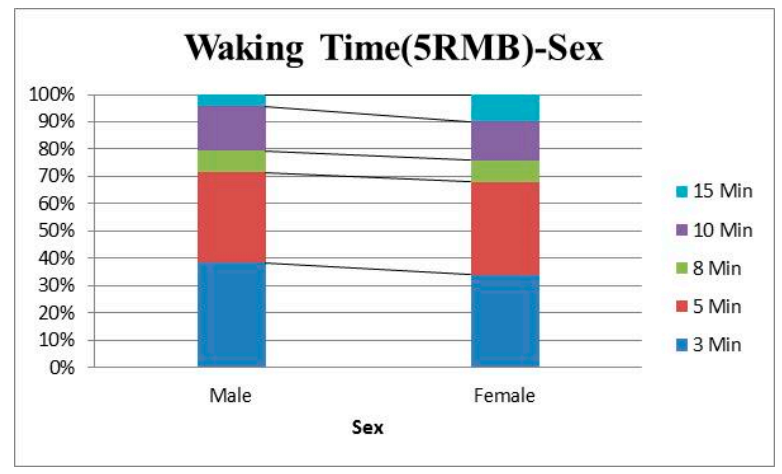

Figure A2. Relationship between Walking Time and Sex (Saving 5 RMB).

Appendix C.2. Case 2: Saving 10 RMB for Parking Fee

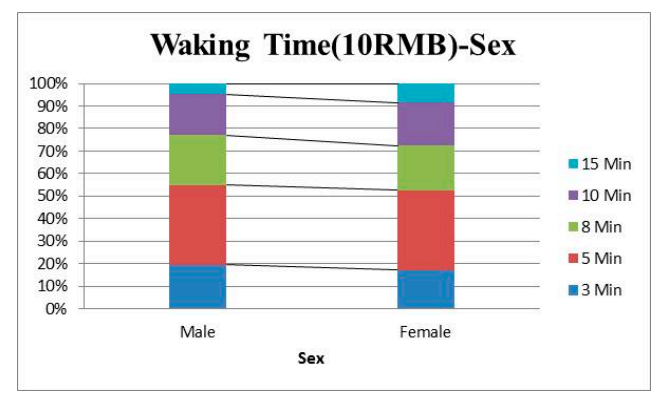

(a)

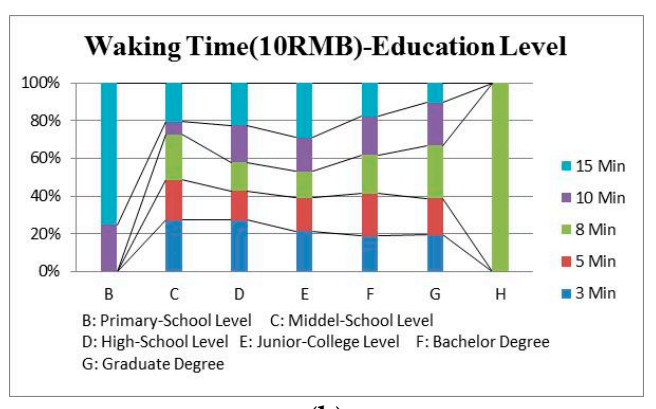

(b)

Figure A3. Relationship between walking time and significant variables (saving $10 \mathrm{RMB}$ ): (a) Relationship between walking time and sex; (b) Relationship between walking time and highest education level. 
Appendix C.3. Case 3: Saving 20 RMB for Parking Fee

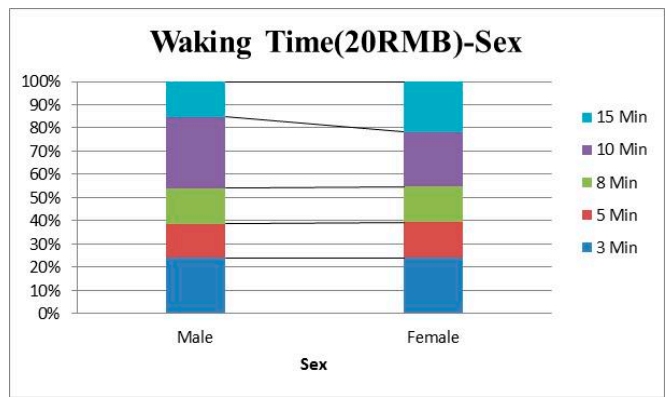

(a)

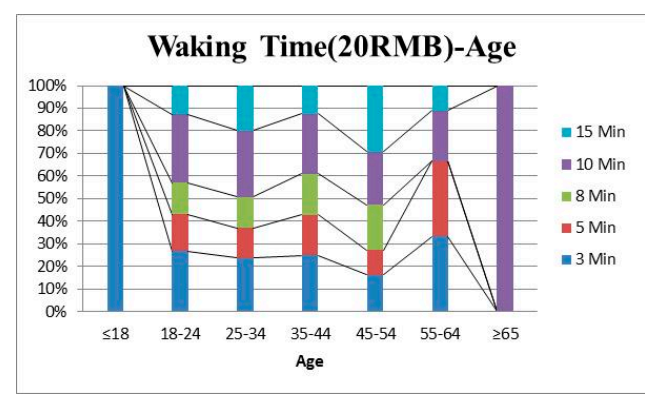

(b)

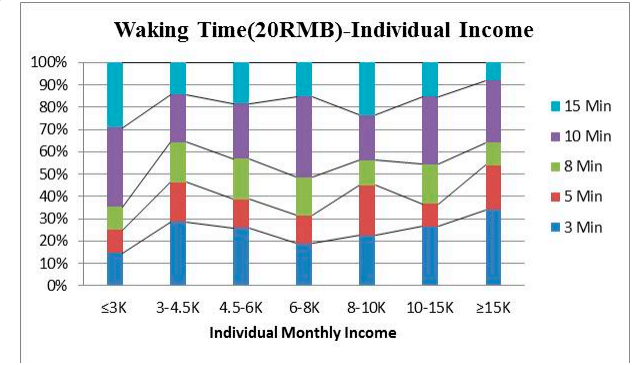

(c)

Figure A4. Relationship between walking time and significant variables (Saving $20 \mathrm{RMB}$ ): (a) Relationship between walking time and sex; (b) Relationship between walking time and age; (c) Relationship between walking time and individual income.

\section{Appendix D. Figures for Comparative Studies of BEV and PHEV Parking Behaviour}

Appendix D.1. Case 1: PHEV with Sufficient Change

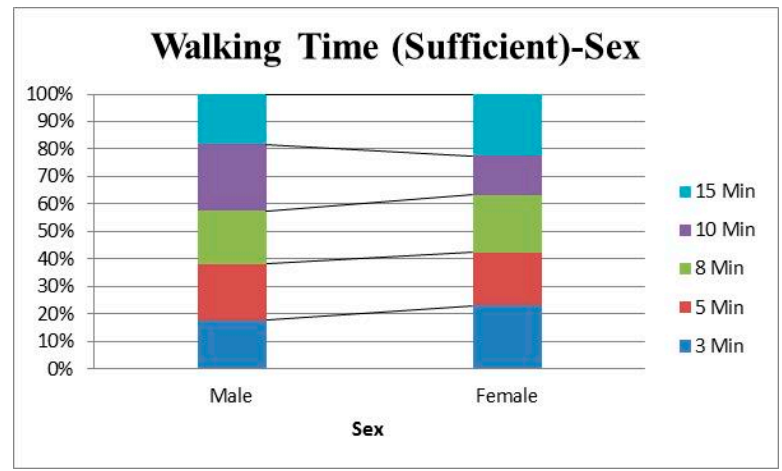

Figure A5. Relationship between walking time and sex for PHEV with sufficient charge. 


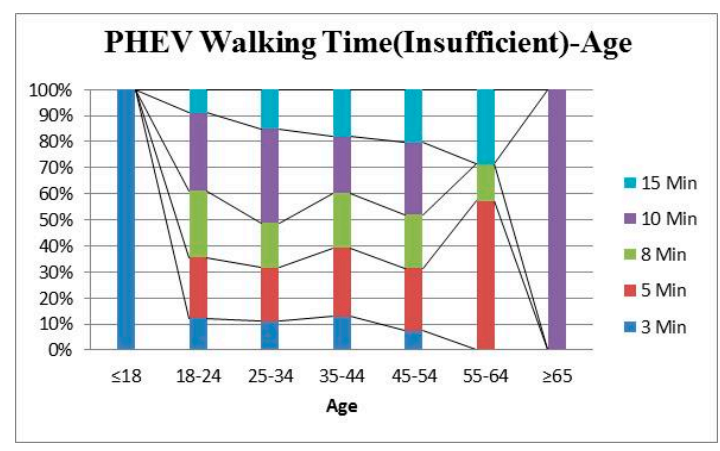

(a)

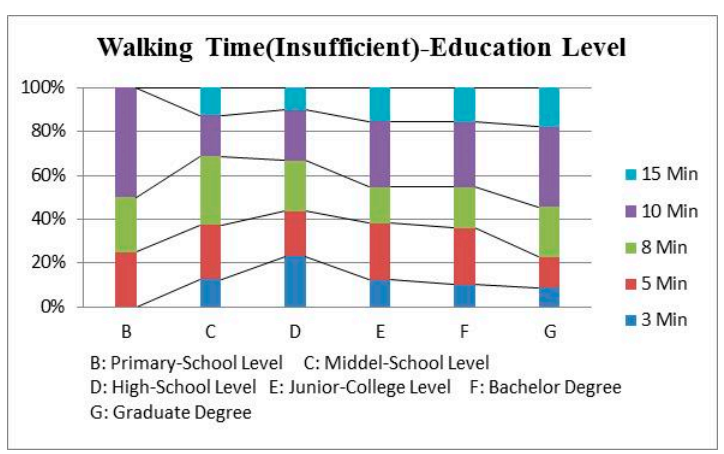

(b)

Figure A6. Relationship between walking time and significant variables for PHEV with insufficient charge: (a) Relationship between walking time and age; (b) Relationship between walking time and education level.

Appendix D.3. Case 3: BEV with Sufficient Change

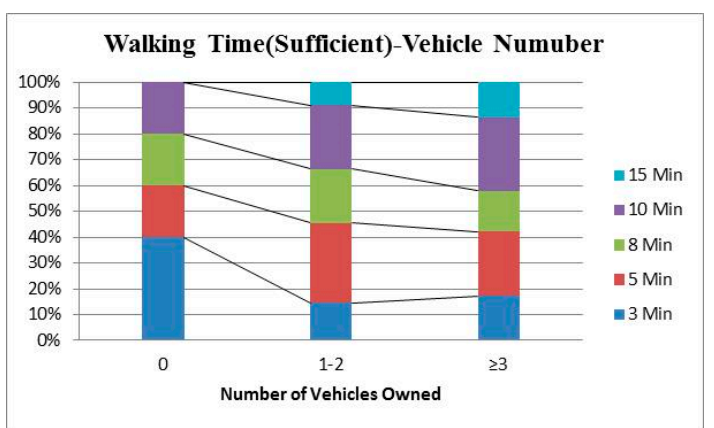

(a)

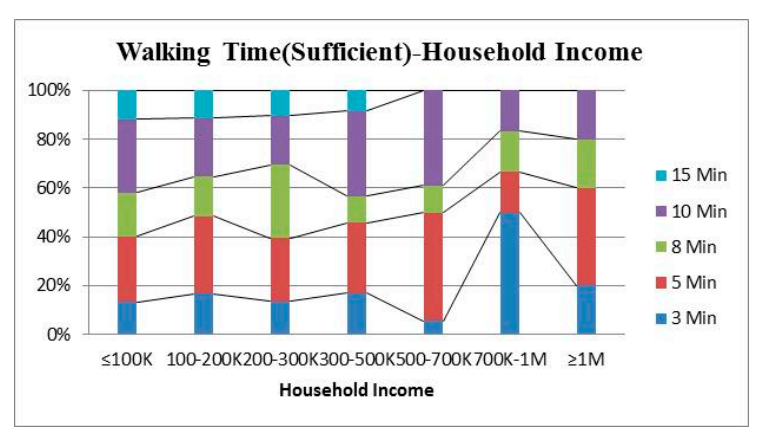

(b)

Figure A7. Relationship between walking time and significant variables for BEV with insufficient charge: (a) Relationship between walking time and vehicle number; (b) Relationship between walking time and household income. 


\section{Appendix E. Figures for the Minimum Driving Range of BEV}

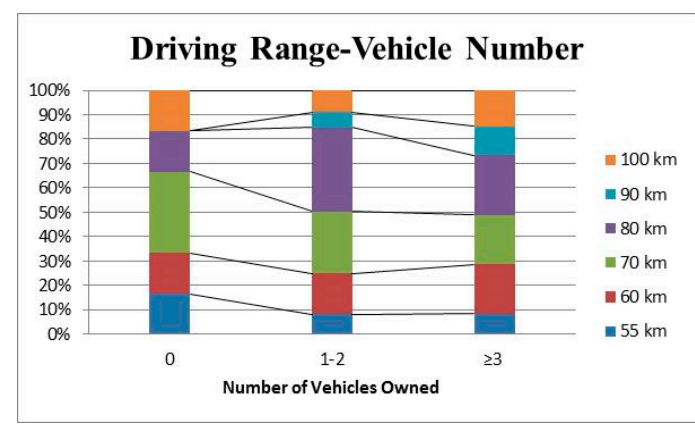

(a)

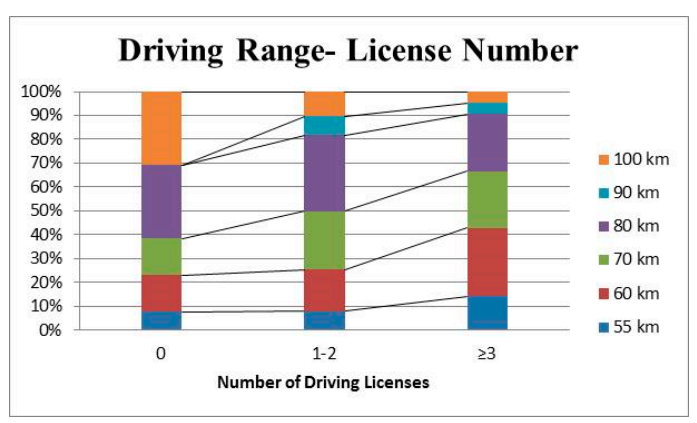

(b)

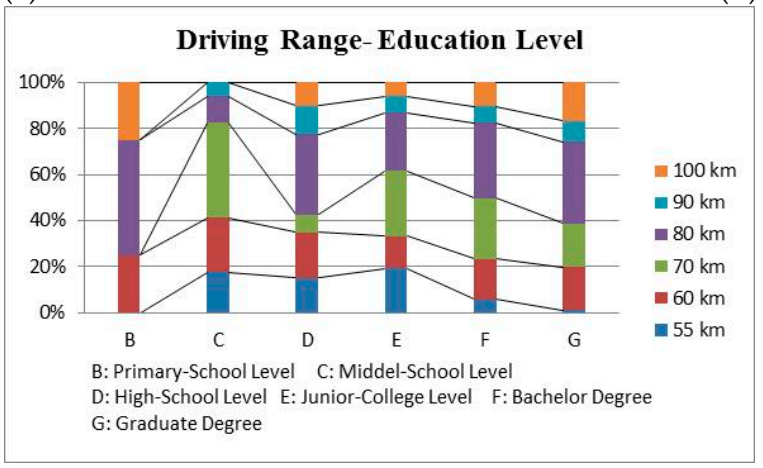

(c)

Figure A8. Relationship between the minimum driving range of BEV and significant variables: (a) Relationship between driving range and vehicle number; (b) Relationship between driving range and license number; (c) Relationship between driving range and vehicle number.

\section{References}

1. Horni, A.; Nagel, K.; Axhausen, K.W. The Multi-Agent Transport Simulation MATSim; Ubiquity: London, UK, 2016.

2. Zhuge, C.; Shao, C.; Wang, S.; Hu, Y. Sensitivity analysis of integrated activity-based model: Using MATSim as an example. Transp. Lett. 2019, 11, 93-103. [CrossRef]

3. Rieser, M.; Nagel, K.; Beuck, U.; Balmer, M.; Rümenapp, J. Agent-oriented coupling of activity-based demand generation with multiagent traffic simulation. Transp. Res. Rec. J. Transp. Res. Board 2007, 2021, 10-17. [CrossRef]

4. Zhuge, C.; Shao, C. Agent-based modelling of locating public transport facilities for conventional and electric vehicles. Netw. Spat. Econ. 2018, 18, 875-908. [CrossRef]

5. Peeta, S.; Ziliaskopoulos, A.K. Foundations of dynamic traffic assignment: The past, the present and the future. Netw. Spat. Econ. 2001, 1, 233-265. [CrossRef]

6. Benenson, I.; Martens, K.; Birfir, S. PARKAGENT: An agent-based model of parking in the city. Comput. Environ. Urban Syst. 2008, 32, 431-439. [CrossRef]

7. Horni, A.; Montini, L.; Waraich, R.A.; Axhausen, K.W. An agent-based cellular automaton cruising-for-parking simulation. Transp. Lett. 2013, 5, 167-175. [CrossRef]

8. van der Waerden, P. PAMELA: Parking Analysis Model for Predicting Effects in Local Areas. Ph.D. Thesis, Eindhoven University of Technology, Eindhoven, The Netherlands, 2012.

9. Tsamboulas, D.A. Parking fare thresholds: A policy tool. Transp. Policy 2001, 8, 115-124. [CrossRef]

10. Brooke, S.; Ison, S.; Quddus, M. Analysing parking search ('cruising') time using generalised multilevel structural equation modelling. J. Transp. Econ. Policy 2018, 52, 202-220.

11. Miller, E.J. Central Area Mode Choice and Parking Demand; Transportation Research Record, The Transportation Research Board: Washington, DC, USA, 1993. 
12. Bradley, M.; Kroes, E.; Hinloopen, E. A joint model of mode/parking type choice with supply-constrained application. In PTRC Summer Annual Meeting, 21st, 1993; University of Manchester: Manchester, UK, 1993.

13. Gillen, D.W. Parking policy, parking location decisions and the distribution of congestion. Transportation 1978, 7, 69-85. [CrossRef]

14. Wilson, R.W. Estimating the travel and parking demand effects of employer-paid parking. Reg. Sci. Urban Econ. 1992, 22, 133-145. [CrossRef]

15. Hess, S.; Polak, J.W. Mixed Logit estimation of parking type choice. In Proceedings of the 83rd Annual Meeting of the Transportation Research Board, The Transportation Research Board, Washington, DC, USA, 11-15 January 2004; pp. 1-23.

16. Albalate, D.; Gragera, A. Empirical evidence on imperfect information in the parking market. J. Transp. Econ. Policy 2018, 52, 322-342.

17. Albalate, D.; Inci, E. Introduction to the Special Issue on the Economics of Parking. J. Transp. Econ. Policy 2018, 52, 181-183.

18. Inci, E.; Lindsey, C.R.; Oz, G. Parking fees and retail prices. J. Transp. Econ. Policy 2018, 52, 298-321.

19. Molenda, I.; Sieg, G. To Pay or Not to Pay for Parking at Shopping Malls: A Rationale from the Perspective of Two-sided Markets. J. Transp. Econ. Policy 2018, 52, 283-297.

20. de Vos, D.; van Ommeren, J. Parking occupancy and external walking costs in residential parking areas. J. Transp. Econ. Policy 2018, 52, 221-238.

21. de Groote, J.; van Ommeren, J.; Koster, H.R. The impact of parking policy on house prices. J. Transp. Econ. Policy 2018, 52, 267-282. [CrossRef]

22. Hampshire, R.C.; Shoup, D. What share of traffic is cruising for parking? J. Transp. Econ. Policy 2018, 52, 184-201.

23. Zhuge, C.; Wei, B.; Dong, C.; Shao, C.; Shan, Y. Exploring the future electric vehicle market and its impacts with an agent-based spatial integrated framework: A case study of Beijing, China. J. Clean. Prod. 2019, 221, 710-737. [CrossRef]

24. Zhuge, C.; Shao, C. Investigating the factors influencing the uptake of electric vehicles in Beijing, China: Statistical and spatial perspectives. J. Clean. Prod. 2019, 213, 199-216. [CrossRef]

25. Zhuge, C.; Shao, C.; Li, X. A Comparative Study of En Route Refuelling Behaviours of Conventional and Electric Vehicles in Beijing, China. Sustainability 2019, 11, 3869. [CrossRef]

26. Tan, K.M.; Ramachandaramurthy, V.K.; Yong, J.Y. Integration of electric vehicles in smart grid: A review on vehicle to grid technologies and optimization techniques. Renew. Sustain. Energy Rev. 2016, 53, 720-732. [CrossRef]

27. Waraich, R.A.; Galus, M.D.; Dobler, C.; Balmer, M.; Andersson, G.; Axhausen, K.W. Plug-in hybrid electric vehicles and smart grids: Investigations based on a microsimulation. Transp. Res. Part C Emerg. Technol. 2013, 28, 74-86. [CrossRef]

28. Knapen, L.; Kochan, B.; Bellemans, T.; Janssens, D.; Wets, G. Activity-based modeling to predict spatial and temporal power demand of electric vehicles in Flanders, Belgium. Transp. Res. Rec. J. Transp. Res. Board 2012, 2287, 146-154. [CrossRef]

29. Sun, X.-H.; Yamamoto, T.; Morikawa, T. Charge timing choice behavior of battery electric vehicle users. Transp. Res. Part D Transp. Environ. 2015, 37, 97-107. [CrossRef]

30. Sun, X.-H.; Yamamoto, T.; Morikawa, T. Fast-charging station choice behavior among battery electric vehicle users. Transp. Res. Part D Transp. Environ. 2016, 46, 26-39. [CrossRef]

31. Xydas, E.; Marmaras, C.; Cipcigan, L.M.; Jenkins, N.; Carroll, S.; Barker, M. A data-driven approach for characterising the charging demand of electric vehicles: A UK case study. Appl. Energy 2016, 162, 763-771. [CrossRef]

32. Latinopoulos, C.; Sivakumar, A.; Polak, J. Response of electric vehicle drivers to dynamic pricing of parking and charging services: Risky choice in early reservations. Transp. Res. Part C Emerg. Technol. 2017, 80, 175-189. [CrossRef]

33. Robinson, A.; Blythe, P.; Bell, M.; Hübner, Y.; Hill, G. Analysis of electric vehicle driver recharging demand profiles and subsequent impacts on the carbon content of electric vehicle trips. Energy Policy 2013, 61, 337-348. [CrossRef]

34. Speidel, S.; Bräunl, T. Driving and charging patterns of electric vehicles for energy usage. Renew. Sustain. Energy Rev. 2014, 40, 97-110. [CrossRef] 
35. Morrissey, P.; Weldon, P.; O'Mahony, M. Future standard and fast charging infrastructure planning: An analysis of electric vehicle charging behaviour. Energy Policy 2016, 89, 257-270. [CrossRef]

36. Franke, T.; Krems, J.F. Understanding charging behaviour of electric vehicle users. Transp. Res. Part F Traffic Psychol. Behav. 2013, 21, 75-89. [CrossRef]

37. Kempton, W. Electric vehicles: Driving range. Nat. Energy 2016, 1, 16131. [CrossRef]

38. Pearre, N.S.; Kempton, W.; Guensler, R.L.; Elango, V.V. Electric vehicles: How much range is required for a day's driving? Transp. Res. Part C Emerg. Technol. 2011, 19, 1171-1184. [CrossRef]

39. Bonges, H.A., III; Lusk, A.C. Addressing electric vehicle (EV) sales and range anxiety through parking layout, policy and regulation. Transp. Res. Part A Policy Pract. 2016, 83, 63-73. [CrossRef]

40. Albert, G.; Mahalel, D. Congestion tolls and parking fees: A comparison of the potential effect on travel behavior. Transp. Policy 2006, 13, 496-502. [CrossRef]

41. Glazer, A.; Niskanen, E. Parking fees and congestion. Reg. Sci. Urban Econ. 1992, 22, 123-132. [CrossRef]

42. Arnott, R.; Rowse, J. Modeling parking. J. Urban Econ. 1999, 45, 97-124. [CrossRef]

43. Ignaccolo, M.; Caprì, S.; Giunta, U.; Inturri, G. Discrete choice model for defining a parking-fee policy on island of Ortigia, Siracusa. J. Urban Plan. Dev. 2006, 132, 147-155. [CrossRef]

44. Arnott, R.; De Palma, A.; Lindsey, R. A temporal and spatial equilibrium analysis of commuter parking. J. Public Econ. 1991, 45, 301-335. [CrossRef]

45. Gillen, D.W. Estimation and specification of the effects of parking costs on urban transport mode choice. J. Urban Econ. 1977, 4, 186-199. [CrossRef]

46. Van Ommeren, J.N.; Wentink, D.; Rietveld, P. Empirical evidence on cruising for parking. Transp. Res. Part A Policy Pract. 2012, 46, 123-130. [CrossRef]

47. Ben-Akiva, M.E.; Lerman, S.R.; Lerman, S.R. Discrete Choice Analysis: Theory and Application to Travel Demand; MIT Press: Cambridge, MA, USA, 1985; Volume 9.

48. Bonsall, P.; Palmer, I. Modelling drivers' car parking behaviour using data from a travel choice simulator. Transp. Res. Part C: Emerg. Technol. 2004, 12, 321-347. [CrossRef]

49. Hess, S.; Polak, J.W. Mixed Logit modelling of parking type choice behaviour. In Transportation Statistics (77-102); Jd Ross Publishing: Plantation, FL, USA, 2009.

50. Wolf, C.C.; Ocklenburg, S.; Ören, B.; Becker, C.; Hofstätter, A.; Bös, C.; Popken, M.; Thorstensen, T.; Güntürkün, O. Sex differences in parking are affected by biological and social factors. Psychol. Res. Prpf 2010, 74, 429-435. [CrossRef]

51. Ahmadi Azari, K.; Arintono, S.; Hamid, H.; Rahmat, R.A.O.K. Modelling demand under parking and cordon pricing policy. Transp. Policy 2013, 25, 1-9. [CrossRef]

52. Langbroek, J.H.M.; Franklin, J.P.; Susilo, Y.O. When do you charge your electric vehicle? A stated adaptation approach. Energy Policy 2017, 108, 565-573. [CrossRef]

53. Philipsen, R.; Schmidt, T.; van Heek, J.; Ziefle, M. Fast-charging station here, please! User criteria for electric vehicle fast-charging locations. Transp. Res. Part F Traffic Psychol. Behav. 2016, 40, 119-129. [CrossRef]

54. Salomon, I. Towards a behavioural approach to city centre parking: The case of Jerusalem's CBD. Cities 1986, 3, 200-208. [CrossRef]

55. Nurul Habib, K.M.; Morency, C.; Trépanier, M. Integrating parking behaviour in activity-based travel demand modelling: Investigation of the relationship between parking type choice and activity scheduling process. Transp. Res. Part A Policy Pract. 2012, 46, 154-166. [CrossRef]

56. Stata, Mlogit-Multinomial (Polytomous) Logistic Regression. Available online: http://www.stata.com/ manuals13/rmlogit.pdf (accessed on 22 March 2016).

57. Macal, C.M.; North, M.J. Tutorial on agent-based modelling and simulation. J. Simul. 2010, 4, 151-162. [CrossRef]

58. Farmer, J.D.; Foley, D. The economy needs agent-based modelling. Nature 2009, 460, 685. [CrossRef]

59. Zhuge, C.; Shao, C. Agent-based modelling of purchasing, renting and investing behaviour in dynamic housing markets. J. Comput. Sci. 2018, 27, 130-146. [CrossRef]

60. Zhuge, C.; Shao, C.; Gao, J.; Dong, C.; Zhang, H. Agent-based joint model of residential location choice and real estate price for land use and transport model. Comput. Environ. Urban Syst. 2016, 57, 93-105. [CrossRef] 
61. Waraich, R.; Axhausen, K. Agent-based parking choice model. Transp. Res. Rec. J. Transp. Res. Board 2012, 2319, 39-46. [CrossRef]

62. Bischoff, J.; Nagel, K. Integrating explicit parking search into a transport simulation. Procedia Comput. Sci. 2017, 109, 881-886. [CrossRef]

(C) 2019 by the authors. Licensee MDPI, Basel, Switzerland. This article is an open access article distributed under the terms and conditions of the Creative Commons Attribution (CC BY) license (http://creativecommons.org/licenses/by/4.0/). 